This item was submitted to Loughborough's Research Repository by the author.

Items in Figshare are protected by copyright, with all rights reserved, unless otherwise indicated.

\title{
Consumers' expectations for product lifetimes of consumer durables
}

\section{PLEASE CITE THE PUBLISHED VERSION}

https://doi.org/10.1109/EGG.2016.7829850

\section{PUBLISHER}

(c) Fraunhofer IZM. Published by the IEEE

\section{VERSION}

AM (Accepted Manuscript)

\section{LICENCE}

CC BY-NC-ND 4.0

\section{REPOSITORY RECORD}

Oguchi, Masahiro, Tomohiro Tasaki, Ichiro Daigo, Tim Cooper, Christine Cole, and Alex Gnanapragasam. 2019. "Consumers' Expectations for Product Lifetimes of Consumer Durables". figshare.

https://hdl.handle.net/2134/34807. 


\title{
Consumers' expectations for product lifetimes of consumer durables
}

Electronics Goes Green, Berlin. 7-9 September 2016.

\author{
Authors \\ Masahiro Oguchi*1, Tomohiro Tasaki1, Ichiro Daigo2, Tim Cooperз, Christine Cole3, Alex Gnanapragasam3
}

1 National Institute for Environmental Studies, Tsukuba, Japan

2 The University of Tokyo, Tokyo, Japan

3 Nottingham Trent University, Nottingham, UK

* Corresponding Author, oguchi.masahiro@nies.go.jp, +81 298502784

Abstract

Product lifetimes are a relevant topic of discussion towards establishing a circular economy, particularly in terms of the reduction of environmental impacts by improving product longevity. Various researchers have developed models to estimate actual lifetimes and have reported case studies for some product categories (e.g. electrical and electronic equipment, and vehicles). However, actual lifetimes may not necessarily meet consumers' expectations. Therefore, an integration of the two perspectives - actual and expected product lifetimes — should prove helpful in optimizing product lifetimes. We proposed different definitions of expected product lifetimes from the consumer perspective and then investigated consumer expectations of the product lifetimes of consumer durables according to these definitions. Several types of EEE were examined as case studies, and questionnaire surveys were conducted. We found that expected lifetimes varied according to the definition used. Expected product lifetimes should be measured by using clearly defined terms to analyse the gaps between actual product lifetimes and consumer expectations.

\section{Introduction}

Product longevity is instrumental in establishing a circular economy and reducing the environmental impacts of mass consumption. Several studies have highlighted the multifaceted issues that influence product lifetimes. Various researchers have developed models to estimate actual lifetimes and have reported case studies for some product categories (e.g., electrical and electronic equipment (EEE) and vehicles) by using existing data. However, these actual lifetimes may not necessarily meet final users' expectations. Past research has revealed this to be the case for some product categories, including EEE [1].

The EU action plan for the circular economy states that the reparability, upgradability, and durability of products will be promoted under the Eco-design Directive and the Eco-design Working Plan for 2015-2017 [2]. When consumers are being encouraged to use their products for longer periods through better product design, it is important to understand the gap between actual lifetimes and consumer expectations, because this gap indicates the potential for extending product lifetimes.

In addition, product lifetimes are determined by more than just physical durability, with both the relative and the absolute degradation of product value playing a significant role as well. When improving product design with the goal of extending product lifetimes, it is thus also important to understand consumer expectations regarding product lifetimes and the factors that affect these expectations.

Therefore, a comparison of the two perspectives - that is, actual and expected product lifetimes—should prove useful in informing researchers, companies, and policymakers as they tackle the challenge of optimizing product lifetimes. Definitions and the methodological framework for actual product lifetimes have been discussed, and large amounts of empirical data on actual product lifetimes have been reported (e.g., see references [3-4]). Some studies have also reported data on expected product lifetimes, but the definitions of expected product lifetimes have not been sufficiently discussed.

Here, we proposed three definitions of expected product lifetimes from consumer perspectives, and we investigated consumer expectations of the lifetimes of several types of EEE according to the different expected product lifetimes we defined.

\section{Definitions of expected product lifetimes}

\subsection{Past studies of expected product lifetimes}

Cooper (2004) reported consumers' expected lifetimes of products in 15 categories, including domestic appliances, consumer electronics, and toys [5]. Expected lifetimes were surveyed through quantitative research undertaken in face-to-face interviews and focus groups with 802 households in the United Kingdom. The expected lifetimes were defined as lifespans considered "reasonable" by the respondent.

The word "reasonable" implies that the expected lifetimes were considered to be realistic expectations on the basis of the consumers' past experiences and perhaps some sort of valuation of the products relative to their price as well. Another study in the United Kingdom by Brook Lyndhurst reported the expected lifetimes of 30 types of 
products, including clothing, furniture, electronics, major appliances, and small appliances [6]. The expected lifetimes were determined in 12 group discussions involving a total of 115 participants. In this case, participants were asked, "How long would you normally expect to use this product for?" The definition of expected lifetime is not entirely clear from the question, but the use of the word "normally" implies that the respondents also may have answered considering their own realistic expectations regarding the various products' lifetimes.

Wieser et al. (2015) were more specific regarding the definitions of expected product lifetimes [7]. They surveyed the expected lifetimes of 21 products, including cars, clothes, consumer electronics, small and major appliances, and furniture, through a large-scale web-based questionnaire survey [7]. They asked respondents, "How long do you expect the products to last or flawlessly function under normal intensity of use?” They reported a summary of the answers to this question as "desired lifetimes." They also surveyed the normal use-times (lifetimes) of the target products by asking the question, "How long do you normally use the products?" (They considered this to be the "reasonable" expected lifetime.) The results showed significant differences between the "desired lifetimes" and the "(reasonable) expected lifetimes." On the basis of this, Wieser et al. pointed out the importance of differentiating between "desired lifetimes" and "(reasonable) expected lifetimes" to capture consumer expectations regarding product lifetimes adequately.

In Japan, Tasaki et al. conducted a mail-in questionnaire survey of 1324 households regarding the expected lifetimes of eight types of EEE [8]. They surveyed the age of products owned by the respondents and the additional number of years that the respondents "will" continue to use their products. They calculated the sum of these two values as the expected total lifetimes of the products. WRAP conducted a similar survey in their study of clothing longevity in the UK [9].

The reported lifetimes in these two studies appear similar to those defined in the three previously mentioned studies [5-7]. However, the expected lifetimes obtained by Tasaki et al. and WRAP include the consumers' willingness or intention to use their products, whereas the results of the other studies do not.

\subsection{Three proposed definitions of expected product lifetime}

Here, we defined "expected product lifetime" from the consumer perspective in three ways: "intended lifetime," "ideal lifetime," and "predicted lifetime."

- "Intended lifetime" represents how long consumers intend to use their products. Intended lifetime reflects consumers' willingness to use a product.

- "Ideal lifetime" represents the length of time for which consumers ideally expect the product to last. Ideal lifetime reflects the highest preference of consumers.

- "Predicted lifetime" represents the length of time for which consumers predict a product will last. Predicted lifetime reflects realistic predictions by consumers on the basis of their past experiences and other relevant factors.

According to these definitions, the expected lifetimes reported by Cooper [5] and Brook Lyndhurst [6] would be classified as predicted lifetimes, and those utilised by Tasaki et al. are intended lifetimes. The "desired lifetimes" of Wieser et al. [7] can be thought of as ideal lifetimes in our typology because they reflect the highest lifetime preferences of consumers.

Measuring expected product lifetimes by using these distinctly different definitions is useful to better understand consumer expectations regarding product lifetimes and to identify the factors affecting differences between actual product lifetimes and consumer expectations.

In addition, it is also necessary to differentiate consumers' general expectations of a certain product type or category from their expectations of products they actually own. For example, Brook Lyndhurst surveyed expected lifetimes in a general sense and included the words "normally" or "usually" in their questions. On the other hand, the more specific expected lifetimes of consumers were surveyed by Tasaki et al., who asked about the products consumers actually owned.

\section{Preliminary survey of expected product lifetimes according to the three definitions}

\subsection{Survey method}

We conducted a questionnaire survey of consumer expectations of product lifetimes for several types of EEE, namely vacuum cleaners, mobile phones (including smartphones and feature phones), digital audio players (including hard drive-based players and flash-based players), and digital cameras.

The survey was conducted by using an Internet-based questionnaire in February and March 2016. In February, 2100 households (participants aged over 20 years old) were asked about their expectations with regards to vacuum cleaners. In March, 1710 individuals were asked about their expectations with regards to mobile phones, digital audio players, and digital cameras. The characteristics of the respondents are summarized in Table 1. 


\begin{tabular}{|c|c|c|c|c|}
\hline \multirow{3}{*}{$\begin{array}{l}\text { Sample size } \\
\text { Gender }\end{array}$} & \multicolumn{2}{|c|}{$\begin{array}{c}\text { Heads of households/ } \\
\text { their spouses }\end{array}$} & \multicolumn{2}{|c|}{ Individuals } \\
\hline & \multicolumn{2}{|l|}{2100} & \multicolumn{2}{|l|}{1710} \\
\hline & & & & \\
\hline Men & 1338 & $(63.7 \%)$ & 1049 & $(61.3 \%)$ \\
\hline Women & 762 & $(36.3 \%)$ & 661 & $(38.7 \%)$ \\
\hline \multicolumn{5}{|l|}{$\overline{\mathrm{Age}}$} \\
\hline $16-19$ & - & & 4 & \\
\hline $20-29$ & 82 & $(3.9 \%)$ & 127 & $(7.4 \%)$ \\
\hline $30-39$ & 328 & $(15.6 \%)$ & 323 & $(18.9 \%)$ \\
\hline $40-49$ & 627 & $(29.9 \%)$ & 497 & $(29.1 \%)$ \\
\hline $50-59$ & 565 & $(26.9 \%)$ & 423 & $(24.7 \%)$ \\
\hline $60-$ & 498 & $(23.7 \%)$ & 336 & $(19.6 \%)$ \\
\hline \multicolumn{5}{|l|}{ Region } \\
\hline Holkkaido & 99 & $(4.7 \%)$ & 82 & $(4.8 \%)$ \\
\hline Tohoku & 100 & $(4.8 \%)$ & 101 & $(5.9 \%)$ \\
\hline Kanto & 942 & $(44.9 \%)$ & 756 & $(44.2 \%)$ \\
\hline Chubu & 291 & $(13.9 \%)$ & 211 & $(12.3 \%)$ \\
\hline Kinki & 399 & $(19.0 \%)$ & 317 & $(18.5 \%)$ \\
\hline Chugoku & 90 & $(4.3 \%)$ & 76 & $(4.4 \%)$ \\
\hline Shikoku & 35 & $(1.7 \%)$ & 43 & $(2.5 \%)$ \\
\hline Kyushu \& Okinawa & 144 & $(6.9 \%)$ & 124 & $(7.3 \%)$ \\
\hline Marriage/children status $\left({ }^{*}\right)$ & & $(0.0 \%)$ & & $(0.0 \%)$ \\
\hline Single without child & 396 & $(18.9 \%)$ & 546 & $(31.9 \%)$ \\
\hline Single with child/children & 10 & $(0.5 \%)$ & 6 & $(0.4 \%)$ \\
\hline Manied without child & 376 & $(17.9 \%)$ & 281 & $(16.4 \%)$ \\
\hline Manied with child/children & 1318 & $(62.8 \%)$ & 877 & $(51.3 \%)$ \\
\hline
\end{tabular}

* Widowed and divorced were included in the "mamied" category.

Table 1: Summary of respondent characteristics

Respondents were asked to provide the following information.

- The number and the purchase/manufacture year of the relevant products they owned.

- The expected remaining lifetimes of the products they owned.

- The frequency of use of the products (or functions of the products) they owned.

- The reasons why they did not use the products they owned (only if they did not use the products

- at all).

- Their level of satisfaction with the products (or functions of the products) they owned.

For the questions on "expected lifetimes," each set of samples was divided into three groups (700 heads of households/their spouses and 570 individuals in each group). Each group was asked a different question to avoid bias stemming from the various definitions of expected lifetimes.

- Group A: For how many years do you intend to use the product you own? (i.e., the intended lifetime)

- Group B: Ideally, for how many years do you expect to use the product you own? (i.e., the ideal

- lifetime)

- Group C: Realistically, how many years do you expect the product you own to last? (i.e., the predicted 
lifetime).

As previously discussed, the expected (remaining) lifetimes investigated in our preliminary survey indicated the consumers' expectations of products that they actually owned, as opposed to a general opinion on these types of appliances.

\subsection{Results and discussion}

\subsubsection{Questionnaire survey results}

Table 2 shows the averages and CVs (coefficients of variation) of the current ages of products owned by the respondents. Vacuum cleaners had the highest average age and mobile phones had the lowest.

\begin{tabular}{|c|c|c|c|}
\hline & $\begin{array}{c}\text { Average } \\
\text { current } \\
\text { age } \\
\text { (years) }\end{array}$ & $\mathrm{CV}$ & $\begin{array}{l}\text { Number } \\
\text { of prod- } \\
\text { ucts }\end{array}$ \\
\hline Vacuum cleaners & 7.2 & $75 \%$ & 2007 \\
\hline Mobile phones & 3.1 & $82 \%$ & 1624 \\
\hline $\begin{array}{l}\text { Digital audio } \\
\text { players }\end{array}$ & 5.5 & $54 \%$ & 640 \\
\hline Digital cameras & 5.5 & $54 \%$ & 1225 \\
\hline
\end{tabular}

\section{Table 2: Summary of age distributions of products owned by the respondents}

Figure 1 shows the distribution of product ages of mobile phones owned by the respondent groups (A,B, and C), for individuals. No notable differences were observed in the results between the respondent groups and the entire sample. The characteristics of the sample households or individuals also showed a similar distribution between the respondent groups. The three groups could therefore be regarded as having similar characteristics and the surveyed expected lifetimes determined by using different definitions could be considered comparable to each other.

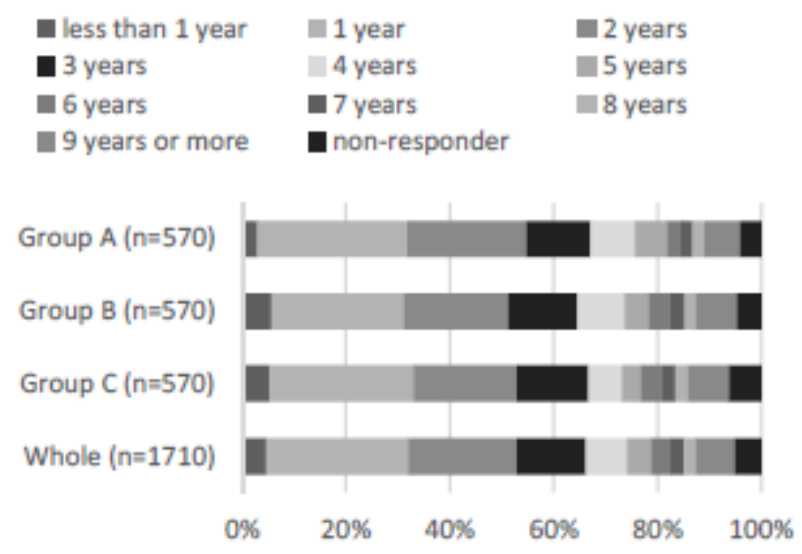

Figure 1: Distributions of current product age distributions of mobile phones owned by the respondents

\subsubsection{Differences in expected lifetimes by definition}

Figure 2 shows the distributions of the expected remaining lifetime answers for the four types of EEE. The results are shown for each of the three different definitions of expected lifetime: intended (A), ideal (B), and predicted (C) remaining lifetimes. The results in the figure are directly comparable between the definitions, as no notable difference was seen in the distribution of product age and the characteristics of the respondents. 
For each of the four products, the ideal lifetimes tended to be longer than the intended lifetimes and the predicted lifetimes, indicating that people considered the reasonable or actual expected lifetimes to be shorter than the ideal lifetimes. This tendency is in agreement with the results of Wieser et al. [7] and demonstrates the importance of differentiating among the proposed definitions when investigating and discussing expected product lifetimes.

\subsubsection{Changes in expectations over time}

Figure 3 shows the differences in expected remaining lifetimes by product age, using mobile phones as an example. Consumer expectations of the remaining lifetimes of their products decreased with time until about 3 years after product purchase. However, after 4 years of use, the expected remaining lifetimes were longer than those of younger products. The results suggested that the expected total lifetimes of mobile phones were longer for older products. A similar trend was observed for all three definitions of expected product lifetime.

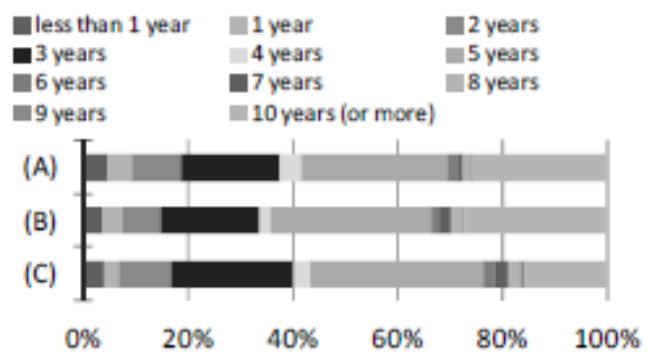

(a) Vacuum cleaners

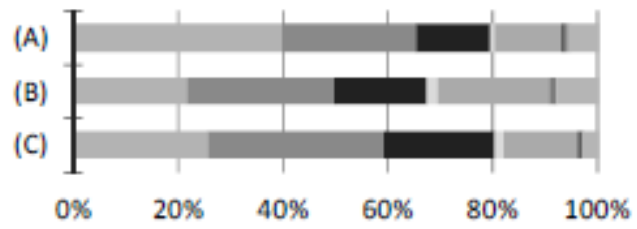

(b) Mobile phones

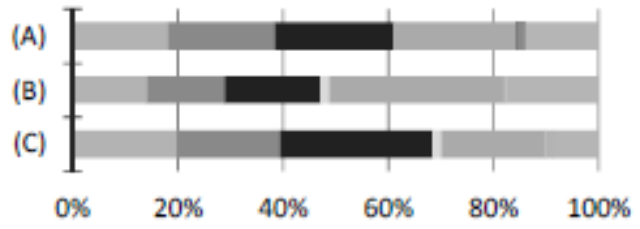

(c) Digital audio players

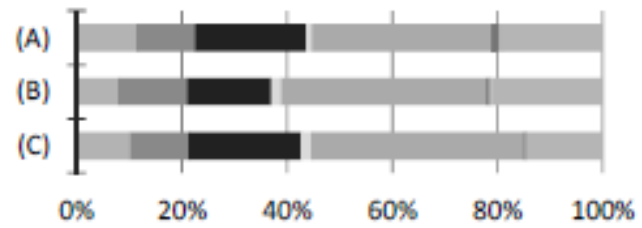

Figure 2: Results of the questionnaire on remaining expected lifetimes of products owned by respondents: (A) intended, (B) ideal, and (C) predicted lifetimes.

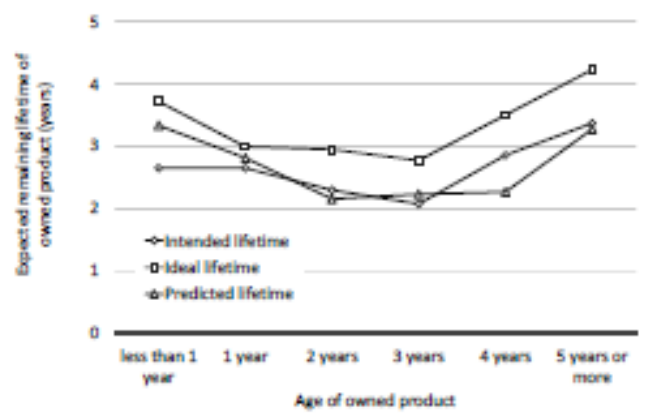

Figure 3: Expected remaining lifetimes of mobile phones by current age of the phone 
Before the survey, we expected that the expected total lifetimes would be shorter for older products, on the basis of the following hypotheses: (1) the remaining lifetimes should be shorter for older products if the (actual) total product lifetime were the same, and (2) expectations regarding the remaining lifetimes would be lower for older products because their condition would be worse and consumer satisfaction would likely lower. The results, however, showed longer expected total lifetimes for older products.

In general, mobile phones have relatively short lifetimes. The average actual lifespan of mobile phones in various countries has been estimated to be several years [10]. However, after consumers have used their products for a certain period of time, they may be motivated to use the products for much longer. It is also possible that the results for the expectations of older products reflect the expectations of those consumers who tend to use products longer. Similarly, the results for younger products may also reflect the expectations of consumers who tend to use their products for a shorter period of time.

\subsubsection{Need to establish a common method of survey of expected product lifetimes}

In our preliminary survey, a non-negligible percentage of respondents answered that their products' expected remaining lifetimes were "10 years (or more)." It is understandable that some consumers wish to use their products as long as possible. However, considering the information on actual product lifetimes, these answers might not reflect reality. This is a limitation of the simple questionnaire survey method. Another approach, such as face-toface interviews, may be needed in combination with a questionnaire survey to solve this problem. A standardised accurate survey method should be developed for quantitative analyses and international comparisons of expected product lifetimes.

\section{Conclusions}

Here, we discussed the definitions of expected product lifetimes from the consumer perspective. Three different definitions of expected product lifetimes were proposed: intended lifetime, ideal lifetime, and predicted lifetime. These definitions should be clearly differentiated when investigating and discussing consumer expectations of product lifetimes.

We investigated consumer expectations regarding the lifetimes of owned products according to the proposed definitions. An Internet-based questionnaire survey was conducted on several types of EEE. The results showed that expected lifetimes varied according to the definitions. To analyse the gaps between actual product lifetimes and consumer expectations it is therefore necessary to measure expected product lifetimes by using clear definitions. There are, however, limitations in investigating expected product lifetimes by using only a simple questionnaire survey. A standardised accurate survey method for quantitative analyses and international comparisons of expected product lifetimes needs to be developed.

\section{Literature}

[1] T. Cooper, and K. Mayers, Prospects for household appliances, Halifax, Canada: Urban Mines, 2000.

[2] European Commission, Closing the loop - An EU action plan for the Circular Economy, COM (2015) 614 final, 2015.

[3] S. Murakami, M. Oguchi, T. Tomohiro, I. Daigo, and S. Hashimoto, "Lifespan of commodities, part I: The creation of a database and its review,” Journal of Industrial Ecology, vol. 14, no. 4, pp. 598-612, 2010.

[4] M. Oguchi, S. Murakami, T. Tasaki, I. Daigo, and S. Hashimoto, "Lifespan of commodities, part II: Methodologies for estimating lifespan distribution of commodities,” Journal of Industrial Ecology, vol. 14, no. 4, pp. 613-626, 2010.

[5] T. Cooper, "Inadequate life? Evidence of consumer attitudes to product obsolescence,” Journal of Consumer Policy, vol. 27, pp. 421-449, 2004.

[6] Brook Lyndhurst, "Public understanding of product lifetimes and durability,” Department for Environment, Food, and Rural Affairs, July 2011.

[7] H. Wieser, N. Troeger, and R. Huebner, “The consumers' desired and expected product lifetimes,” in Product Lifetimes And The Environment (PLATE) 2015 Conference Proceedings, T. Cooper, N. Braithwaite, M. Moreno, and G. Salvia, Eds. Nottingham Trent University, 2015, pp. 388-393.

[8] T. Tasaki, A. Terazono, and Y. Moriguchi, “A survey on consumer disposal behavior of electric home appliances for encouraging products' longterm use and reuse,” Journal of the Japan Society of Waste Management (Haikibutsu Gakkai Ronbunshi), vol. 15, no. 4, pp. 310-319, 2004 (in Japanese with English abstract, figures, and tables).

[9] E. Langley, S. Durkacz, and S. Tanase, Summary report: clothing longevity and measuring active use. Banbury: Ipsos MORI for WRAP. April 2013.

[10] M. Polák, and L. Drápalová, "Estimation of end of life mobile phones generation: The case study of the Czech Republic,” Waste Management, vol. 32, no. 8, pp. 1583-1591, August 2012. 